\title{
Life history and population dynamics of the opportunistic polychaete Capitella sp. I in relation to sediment organic matter
}

\author{
Tina Ramskov, Valery E. Forbes* \\ Centre for Integrated Population Ecology, Department of Environmental, Social and Spatial Change, Roskilde University, \\ PO Box 260, Universitetsvej 1, 4000 Roskilde, Denmark
}

\begin{abstract}
Capitella sp. I is a deposit-feeding polychaete that occurs in estuarine and marine environments and that shows boom-bust population dynamics in response to organic pollution. A lifecycle experiment was carried out to quantify the relative importance of individual life-history traits for driving the dynamics of Capitella sp. I populations in response to changes in sediment organic matter concentrations. Individual-level effects were estimated as changes in survival, reproductive characteristics, and growth. Effects at the population-level were assessed by integrating the measured life-history traits in a simple 2-stage demographic model that was used to estimate the population growth rate $(\lambda)$. Low organic content considerably impaired individual life-history traits and, as a consequence, $\lambda$. The results of the present study suggest that the minimum organic matter concentration for the maintenance, survival and growth of Capitella sp. I is $0.2 \%$ TOM (total organic matter), and that sediments with $<0.5 \%$ TOM would not support Capitella sp. I reproduction. The change in $\lambda$ in response to sediment organic concentration was primarily attributable to effects on time to first reproduction, which explained, on average, $47 \%$ of the variance in $\lambda$. Treatment effects on juvenile survival and fecundity explained, on average, 26 and $24 \%$, respectively, of the observed treatment effect on $\lambda$, whereas adult survival and time between broods together contributed about $3 \%$ to the effect on $\lambda$. The threshold between population extinction and population increase was sharp, which suggests that relatively small changes in organic loading can have dramatic consequences for the population dynamics in this species.
\end{abstract}

KEY WORDS: Deposit feeder $\cdot$ Food limitation $\cdot$ Population growth rate $\cdot$ Demographic analysis

Resale or republication not permitted without written consent of the publisher

\section{INTRODUCTION}

Benthic deposit feeders play a key role in the cycling of organic matter in marine sediments (Lopez \& Levinton 1987). Sedimentary organic matter may be of different origin (i.e. autochthonous versus allochthonous) and composition (in terms of bioavailability, nutritional value, degradability), and, since it is influenced by hydrologic conditions (e.g. salinity, temperature, winds, tide), organic matter characteristics may change seasonally in terms of both quantity and quality (Tenore 1988, Grémare et al. 1997, Rossi et al. 2001). Benthic deposit feeders meet their nutritional requirements from the organic fraction of ingested sediment, and particles available for ingestion by deposit feeders are a complex mixture of living and nonliving organic matter, such as dead plant and animal remains, bacteria, microalgae and fungi (Lopez \& Levinton 1987). However, as sediment is a poor food source in itself (the organic content of marine sediment is usually $<5 \%$; Lopez \& Levinton 1987), deposit feeders are generally considered to be food limited. Consequently, food limitation is likely to control population density and dynamics in field populations of such organisms.

Population dynamics of deposit-feeding polychaetes, e.g. Capitella spp., are well known to respond to chan- 
ges in sediment organic content, and in areas of organic pollution (e.g. under fish farms [Tsutsumi 1987], in areas of oil spills [Sanders et al. 1980], near sewage outfalls [Mendez et al. 1997]), populations of this sibling species complex can reach densities of up to $400000 \mathrm{~m}^{-2}$ (Mendez et al. 1997). Capitella sp. I is a highly opportunistic member of the C. capitata sibling species complex, and as such often plays a key role in recolonization and bioremediation of organically polluted sediments. The present study was designed to quantify the responses of individual life-history traits, relating to the survival, growth and reproduction of Capitella sp. I, to manipulations of sediment organic matter concentration and to determine their relative importance for driving the population dynamics of this species in response to changing food availability.

Sediment organic content was manipulated by removing natural organic material with hydrogen peroxide and then enriching the sediment with different amounts of a well-defined food source (i.e. baby cereal, fish food and dried spinach, mixed in equal ratios, by weight) to obtain sediment treatments of similar food quality but different food quantities. The food source was added in amounts to achieve a range in total organic matter of $\sim 0$ to $3 \%$ dry weight (DW) in sediment, a range in total carbon of $\sim 1$ to $12 \mathrm{mg} \mathrm{C} \mathrm{g}^{-1}$ DW sediment, and a range in total nitrogen of $\sim 0$ to $1 \mathrm{mg} \mathrm{N}\left(\mathrm{g}^{-1}\right.$ DW sediment. These levels of organic matter are within the range reported for natural sediments (e.g. the shallow estuary Kertinge Nor, Denmark [Hansen \& Kristensen 1997], and the coastal wetlands of Taiwan [Hu et al. 2003]). Given the difficulties in appropriately characterizing natural sediment organic matter (Lopez \& Levinton 1987), we chose to manipulate organic content using an artificial food mixture that could be unambiguously characterized in terms of its composition and maintained at a constant nutritional quality. The particular food mixture that we chose has previously been shown to enhance growth and reproduction in Capitella sp. I and other depositfeeding invertebrates when added to natural sediment (e.g. Jacobsen et al. 1996, Linke-Gamenick et al. 2000) and is used routinely in our laboratory to maintain long-term cultures of deposit feeders.

\section{MATERIALS AND METHODS}

General. Sediment used in maintenance of worm cultures and experimental treatments was collected from a shallow subtidal area in Isefjorden $\left(55^{\circ} 40^{\prime} \mathrm{N}\right.$, $11^{\circ} 47^{\prime} \mathrm{E}$, Munkholm, Denmark), sieved in deionized water through a $250 \mu \mathrm{m}$ mesh screen and allowed to settle. Subsequently, the overlying deionized water was replaced with seawater (31\%o salinity [S]). Sedi- ment was stored at $-20^{\circ} \mathrm{C}$ until use. Cultures of Capitella sp. I (worms originally obtained from Setauket Harbor, New York, USA, and identified by J. P. Grassle) have been reared in the laboratory at Roskilde University for many years. From these cultures individuals of Capitella sp. I were collected to establish a new stock culture that was reared for at least 3 generations prior to the experiment. Worms were cultured in an aquarium (10 l) containing sediment ( $2 \mathrm{~cm}$ layer, $\geq 250 \mu \mathrm{m})$ and continuously aerated seawater $(31 \% \mathrm{~S})$, and maintained at constant temperature $\left(21^{\circ} \mathrm{C}\right)$. As a supplementary food source, a mixture of equal ratios (by weight) of ground commercial fish food (Tetramin, Tetra Werke), baby cereal (Milpo, Milupa A/S), and dried spinach was regularly added to the stock culture.

Chemical analysis. Sediment samples were homogenized prior to chemical analysis. Total organic matter content (TOM) was determined by loss of mass on ignition after combusting dried $\left(24 \mathrm{~h}\right.$ at $\left.105^{\circ} \mathrm{C}\right)$ sediment samples at $550^{\circ} \mathrm{C}$ for $6 \mathrm{~h}$. Total carbon (TC) and total nitrogen (TN) contents were determined by elemental analysis of samples of known weight (using a Carlo Erba model EA 1110 CHNS element analyzer, CE Instruments), without prior acidification (Charles et al. 1995), and it is assumed that the measured values reflect total organic carbon (TOC) and total organic nitrogen (TON) concentrations, respectively (Linton \& Taghon 2000). After chemical analysis sediments were kept frozen $\left(-20^{\circ} \mathrm{C}\right)$ until use.

Experimental food treatments. Field-collected sediment was cleaned twice for $8 \mathrm{~h}\left(21^{\circ} \mathrm{C}\right)$ in $30 \%$ hydrogen peroxide $\left(\mathrm{H}_{2} \mathrm{O}_{2}\right)$ to remove organics (modified after the method of Decho \& Lopez 1993). Subsequently, the digested sediment was washed in deionized water several times to remove residual peroxide. The rinsed sediment was analyzed for organic matter content, and, since it was not entirely organic free (i.e. $0.69 \pm 0.02 \%$ DW in sediment; $\mathrm{n}=2$ ), the procedure was repeated, resulting in a more acceptable organic content closer to $0 \%$. The peroxide-treated sediment had a TOM, TC, and TN content of $0.212 \pm 0.014 \%$ DW in sediment $(\mathrm{n}=2), 0.096 \pm 0.052 \%$ DW in sediment $(\mathrm{n}=2)$, and $0.001 \pm 0.0005 \% \mathrm{DW}$ in sediment $(\mathrm{n}=2)$, respectively. A mixture (1:1:1 by weight) of ground commercial fish food (Tetramin, Tetra Werke), dried baby cereal (Milpo, Milupa A/S), and dried spinach was added to the peroxide-treated sediment as a food source. The food mixture was ground with a mortar and pestle and sieved through a $250 \mu \mathrm{m}$ mesh screen to obtain a similar maximum particle size as the sediment used in experimental treatments. The content of the mixture was $92.19 \pm 0.01 \%$ TOM DW in sediment $(\mathrm{n}=2), 37.31 \pm 0.37 \%$ TC DW in sediment $(\mathrm{n}=3)$, and $4.32 \pm 0.13 \%$ TN DW in sediment $(n=3)$. The food mixture and peroxide-treated sediment were mixed in dif- 
ferent quantities, ground, and placed on a shaking table overnight to ensure homogenized treatments. After homogenization, the experimental sediments were analyzed for TOM, TC, and TN (Table 1), subsequently portioned $(2 \mathrm{~g} \mathrm{DW})$, and frozen $\left(-20^{\circ} \mathrm{C}\right)$ until use. Experimental treatments will be referred to as 0 , $0.25,0.5,0.75,1$, and $3 \%$ TOM, respectively.

Experimental design. Brooding females were isolated from the stock culture, pooled in a Petri dish containing seawater, and gently removed from their brood tubes. Subsequently, brood tubes containing developing embryos were randomly selected and individually placed in Petri dishes (5 cm in diameter, $1 \mathrm{~g}$ DW of experimental sediment, $10 \mathrm{ml}$ seawater), which were maintained at $21^{\circ} \mathrm{C}$ in the dark. Within several to $24 \mathrm{~h}$ eggs hatched into larvae that settled into the sediment and metamorphosed into juvenile worms. When reared for $5 \mathrm{~d}$, juveniles from the same treatment group were pooled in a Petri dish containing seawater. The minimum number of larvae hatched per treatment was 40 , and consequently 40 juveniles were randomly collected from each treatment group and transferred to a new Petri dish. Body volumes of individual juveniles were measured (see 'Data analysis' for description of method), and subsequently the 40 juveniles from the same treatment group were evenly and randomly assigned to 2 Petri dishes ( $5 \mathrm{~cm}$ in diameter) containing the corresponding experimental sediment (2 $\mathrm{g} \mathrm{DW})$ and seawater $(8 \mathrm{ml}, 31 \% \mathrm{~S})$; i.e. we used 2 replicate dishes per treatment, each dish containing 20 juveniles. The sediment and overlying seawater were $0.5 \mathrm{~cm}$ in height to enhance oxygen diffusion and prevent anoxia in the sediment. To minimize water evaporation, Petri dishes were placed in a box, covered with wet paper tissues and aluminum foil, and kept in the dark at $21^{\circ} \mathrm{C}$. Every second day overlying water was renewed. On each census day, juveniles were removed from the sediment, survival was noted, and juveniles were reassigned to their corresponding treatment dishes containing new experimental sediment and seawater. Petri dishes were monitored weekly until juve-

Table 1. Characteristics of experimental sediment treatments (i.e. TOM treatments). TOM, TC, and $\mathrm{TN}$ represent total organic matter (\% DW in sediment), total carbon (mg C g ${ }^{-1}$ DW sediment), and total nitrogen (mg $\mathrm{N} \mathrm{g}^{-1} \mathrm{DW}$ sediment), respectively. Data presented are means of 2 to 3 replicate samples $( \pm 1 \mathrm{SD})$

\begin{tabular}{|c|c|c|c|}
\hline TOM treatmen & ht $\mathrm{TOM}$ & $\mathrm{TC}$ & $\mathrm{TN}$ \\
\hline $0 \%$ & $0.19 \pm 0.011$ & $0.96 \pm 0.523$ & $0.01 \pm 0.001$ \\
\hline $0.25 \%$ & $0.14 \pm 0.004$ & $1.87 \pm 0.296$ & $0.09 \pm 0.008$ \\
\hline $0.5 \%$ & $0.53 \pm 0.076$ & $2.55 \pm 0.158$ & $0.23 \pm 0.024$ \\
\hline $0.75 \%$ & $0.82 \pm 0.013$ & $3.20 \pm 0.296$ & $0.27 \pm 0.027$ \\
\hline $1 \%$ & $1.19 \pm 0.009$ & $4.00 \pm 0.269$ & $0.43 \pm 0.034$ \\
\hline $3 \%$ & $3.00 \pm 0.084$ & $12.39 \pm 2.722$ & $1.21 \pm 0.368$ \\
\hline
\end{tabular}

niles reached the mature adult stage, and in the present study juveniles were regarded as adults when it was possible to distinguish males and females morphologically (presence of genital spines in males and ovaries in females). As soon as a female and a male matured within a treatment group, they were paired and transferred to vials ( $2 \mathrm{~g}$ DW of sediment, $8 \mathrm{ml}$ seawater, $31 \% \mathrm{~S}$ ). The experimental design aimed for 10 replicate pairs of worms per treatment; however, for some treatments fewer than 10 pairs were available. All vials were monitored once a week until there were no remaining survivors (i.e. after $162 \mathrm{~d}$ ). On each census day, worms were removed from the sediment, and data on survival, body volume, and reproduction were recorded. Subsequently, worms were returned to their corresponding treatments with new experimental sediment and seawater. The following life-history parameters were estimated: agespecific survival, age at maturity, age at first reproduction (appearance of brood tubes), numbers of broods per female, numbers of eggs per brood, time between broods, and population growth rate. Age at sexual maturity was distinguished from age at first reproduction in order to test for possible differences between the proportion of worms reaching morphological maturity and the proportion of mature worms that actually reproduced.

Data analysis. At the start of the experiment, the body volumes of $5 \mathrm{~d}$ old juveniles were measured ( $\mathrm{n}=$ 40 per treatment), and subsequently worm body sizes were measured every week until worms had reproduced for the first time. Individual worms were videotaped with a camera connected to a dissecting microscope. Body length $(L, \mathrm{~mm})$ and area $\left(A, \mathrm{~mm}^{2}\right)$ were measured (3 replicate measures per individual) using an image-analysis software program (SigmaScan Pro software, Ver. 5.0.0., SPSS). Worms were assumed to be cylindrical in shape, and individual worm body volumes $\left(\mathrm{BV}, \mathrm{mm}^{3}\right.$ ) were estimated as $\mathrm{BV}=\pi A^{2} / 4 L$ (Self $\&$ Jumars 1978). Volume-specific growth rates $(G, \%$ body volume change individual ${ }^{-1} \mathrm{~d}^{-1}$ ) were estimated between census days until juveniles reached sexual maturity, following Kaufmann (1981):

$$
G=\left(\operatorname{lnB} V_{\text {final }}-\ln B V_{\text {initial }}\right) / d
$$

where $d$ is time in days.

For demographic analysis, population growth rate $(\lambda)$ was estimated for each treatment by fitting the agespecific data on survival and fecundity to a 2-stage model (Calow \& Sibly 1990, Calow et al. 1997):

$$
1=n S_{\mathrm{j}} \lambda^{-t \mathrm{j}}+S_{\mathrm{a}} \lambda^{-t \mathrm{a}}
$$

where $n$ is the average number of eggs per brood per reproductive individual per breeding attempt, $S_{\mathrm{j}}$ represents juvenile survival (the probability that a juvenile survives from birth to first reproduction), $S_{\mathrm{a}}$ represents adult survival (the probability that an adult survives be- 
tween breeding attempts averaged over the reproductive period), $t_{\mathrm{j}}$ is the time to first reproduction, and $t_{\mathrm{a}}$ is the average time between breeding attempts. The reproductive period is defined as the time between first and last breeding attempts averaged for each treatment. In cases of 1 breeding attempt per individual, the second term to the right of the plus sign drops out of the equation, and in the present analysis the estimation of $t_{\mathrm{a}}$ is based on individuals reproducing at least twice during the reproductive period (i.e. $7,10,10$, and 9 female worms per replicate in the $0.5,0.75,1$ and $3 \%$ TOM treatments, respectively). All time units to calculate $\lambda$ are expressed in weeks. Treatment effects on mean $\lambda$ were analyzed by calculating $95 \%$ confidence intervals on $\lambda$, where confidence intervals are obtained as the square root of the total variance in $\lambda$ (i.e. the sum of the variance contributions from each of the life-history traits contributing to $\lambda$ ), following the analytical method of Sibly et al. (2000). Also, the relationship between $\lambda$ and the corresponding life-history traits was examined by applying elasticity and decomposition analyses (Levin et al. 1996), in which the proportional sensitivities and the relative contributions of life-history traits to the observed effect on $\lambda$, respectively, were estimated according to Forbes et al. (2001). Since $S_{\mathrm{j}}$ is dependent on $t_{\mathrm{j}}$, the variable $p_{\mathrm{j}}$ was defined such that $S_{\mathrm{j}}=p_{\mathrm{j}}{ }^{{ }_{j}}$ and used in the elasticity and decomposition analyses. For consistency we define $p_{\mathrm{a}}$ such that $p_{\mathrm{a}}=S_{\mathrm{a}}$.

Statistics. Chemical properties of sediment treatments (TOM, TC, and TN contents) were analyzed using 1-way analysis of variance (ANOVA). Treatment effects on juvenile survival (the proportion surviving after $1 \mathrm{wk}$ of exposure; i.e. 5 to $12 \mathrm{~d}$ of age), lifespan (females and males separately), body volume at the start of the experiment (i.e. $5 \mathrm{~d}$ of age), volume-specific growth rate during the first sampling period (i.e. from 5 to $12 \mathrm{~d}$ of age), age and size at maturity (females and males separately), female age and size at first reproduction, length of the reproductive period, time between broods, number of broods, total number of eggs, and brood size were compared using ANOVA. When significant main effects were detected in ANOVA, Tukey's pairwise comparisons tests were performed. To test the extent to which differences in reproductive output at first breeding attempt among treatments could be explained by differences in female body volume or age, analyses of covariance (ANCOVA) of reproductive output, with body size or age as covariates were performed. Parameters for which single values per treatment were obtained (i.e. adult survival probability between broods, percent reproducing individuals) were compared qualitatively. Differences in $\lambda$ between pairs of treatments were considered significant if the analytically determined $95 \%$ confidence intervals did not overlap. Prior to analysis, assumptions of normality and homogeneity of variances were checked by examination of notched box plots and by Levene's test, respectively. Data are presented as means $( \pm 1 \mathrm{SD})$ unless otherwise stated. For all statistical analyses, significance was defined as $\mathrm{p} \leq 0.05$ and marginal significance as $0.05<\mathrm{p} \leq 0.1$. All statistical analyses were conducted using Systat Ver. 10 (Systat software).

\section{RESULTS}

\section{Sediment characteristics}

The characteristics of the experimental sediments (i.e. TOM, TC, and TN) are shown in Table 1. TOM content differed among all pairs of treatments (Tukey, $p<0.048$ ) with the exception of the 0.25 and $0.5 \%$ TOM treatments (Tukey, $\mathrm{p}=0.200$ ). The carbon and nitrogen content were both significantly higher in $3 \%$ TOM compared to all other treatments (Tukey, $\mathrm{p} \leq 0.001$ ), whereas no significant differences in TC or TN were found among the other food concentrations. Experimental sediments were not characterized for carbon and nitrogen contents during the course of the experiment, but by assigning worms to new vials containing fresh experimental sediment every week, we are confident that average organic matter concentrations remained near the initial measured values, and that differences between treatments were maintained.

\section{Survival}

Treatment had a strong effect on juvenile survival, and the proportion of juveniles surviving after $1 \mathrm{wk}$ of exposure (out of 40 juveniles in total) differed significantly among treatments (ANOVA, $p=0.011$ ). Juveniles fed on $0 \%$ TOM had significantly lower survival $(\sim 65 \%)$ (Tukey, $\mathrm{p} \leq 0.033)$ than juveniles in sediments of $\geq 0.75 \%$ TOM ( 93 to $95 \%$ survival), and within $6 \mathrm{wk}$ of exposure every juvenile in $0 \%$ TOM had died. In $0.25 \%$ TOM juvenile survival was marginally reduced $(\sim 73 \%)$ (Tukey, $p=0.077$ ) compared to the 0.75 and $3 \%$ TOM treatments. Treatment did not affect average lifespan of male or female worms (ANOVA, $p \geq 0.110$ ). Juvenile survival values used for the demographic analysis (i.e. $S_{\mathrm{j}}=$ the proportion of juveniles surviving from birth to first reproduction) were $0.63,0.83,0.85$, and 0.78 for the $0.5,0.75,1$, and $3 \%$ TOM treatments, respectively, and adult survival values (i.e. $S_{\mathrm{a}}=$ the proportion of adults surviving between breeding attempts, averaged over the breeding period) were $0.98,0.93,0.89$, and 0.97 , respectively. 


\section{Growth and development to sexual maturity}

At the start of the experiment average body volume of $5 \mathrm{~d}$ old juveniles differed significantly among treatments (Table 2) (ANOVA, p < 0.001), where worms in $3 \%$ TOM were significantly larger (Tukey, $\mathrm{p} \leq 0.006$ ) than worms in $0,0.5$, and $1 \%$ TOM (for data pooled among these treatments, the average worm volume was $0.001 \pm$ $0.000 \mathrm{~mm}^{3}$ ), and where worms in $0.25 \%$ TOM were significantly larger (Tukey, $\mathrm{p} \leq 0.011$ ) than worms in 0.5 and $1 \%$ TOM (treatments pooled give a mean of $0.001 \pm$ $0.000 \mathrm{~mm}^{3}$ ). Although the differences are significant, they are small compared to body sizes reached during the experiment, and body sizes of individual $5 \mathrm{~d}$ old juveniles were all smaller than $0.005 \mathrm{~mm}^{3}$.

Growth responses differed among treatments, and differences in average worm size $\left(\mathrm{mm}^{3}\right)$ were apparent on every census day (Table 2). Treatment had a strong effect on volume-specific growth rate $(G)$ already during the first sampling period (from 5 to $12 \mathrm{~d}$ of age; Fig. 1). During the remainder of the experiment growth rate declined with age in all treatments, and differences in $G$ among treatments became less pronounced (Fig. 1). In $0.25 \%$ TOM, 11 juveniles (out of 40 ) survived to the end of the exposure period; however, only 7 of these matured. Worms fed on $0 \%$ TOM barely grew and never sexually matured. Average body volumes at sexual maturity differed significantly among treatments (ANOVA, p < 0.001). Worms in $3 \%$ TOM were significantly larger (Tukey, $\mathrm{p} \leq 0.014$ ) than worms in all other treatments, and worms fed on $0.25 \%$ TOM matured at significantly smaller body volumes (Tukey, $\mathrm{p}=0.031$ ) than worms in $0.75 \% \mathrm{TOM}$, and at marginally smaller body volumes (Tukey, $p=0.071$ ) than worms fed on $1 \%$ TOM. Treatment also had a strong effect on average time to sexual maturity (ANOVA, $p<$ 0.001). Maturation time was significantly delayed for worms in 0.25 and $0.5 \%$ TOM (Tukey, p < 0.001) compared to worms fed on sediments with TOM contents of $\geq 0.75 \%$ TOM (Fig. 2). In addition worms in $0.25 \%$

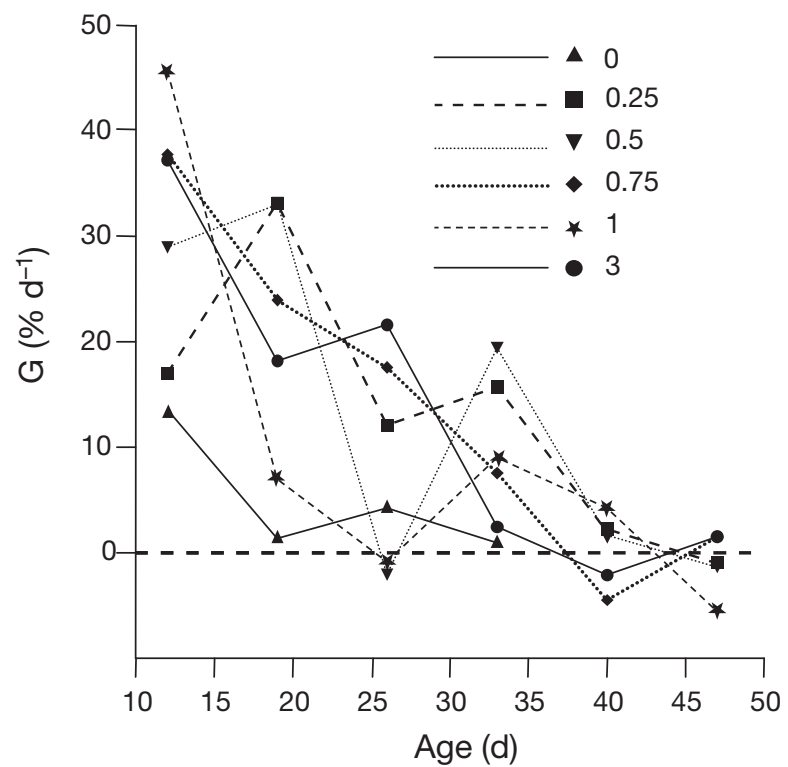

Fig. 1. Capitella sp. I. Mean relative growth rate $\left(G, \% \mathrm{~d}^{-1}\right)$ from $5 \mathrm{~d}$ of age until sexual maturity. Key shows sediment treatments (total organic matter [TOM], \% DW in sediment). Worms in the $0 \%$ TOM did not sexually mature; however, growth rate is included for comparison

TOM matured significantly later (Tukey, p < 0.001) than worms in $0.5 \%$ TOM. In all treatments, juveniles matured either into females or males (i.e. no hermaphrodites were found), and no detectable differences were found in either age at maturity $(p \geq 0.144)$ or size at maturity $(p \geq 0.252)$ between genders.

\section{Reproductive characteristics}

Due to high mortality, only 3 replicate pairs reached maturity in $0.25 \%$ TOM; however, none of these ever reproduced. In all other treatments, at least $80 \%$ of females produced eggs, and $1 \%$ TOM was the only treatment in which every replicate pair reproduced

Table 2. Capitella sp. I. Average body volume $\left( \pm 1 \mathrm{SD}, \mathrm{mm}^{3}\right)$ of individuals in the different TOM treatments (\% DW in sediment) measured on each census day. -: indicates not measurable due to high mortality. Body volumes estimated at the start of the experiment (i.e. when juveniles were $5 \mathrm{~d}$ old) are given to 3 decimal places, whereas body volumes on all other census days are given to 2 decimal places for clarity

\begin{tabular}{|c|c|c|c|c|c|c|}
\hline \multirow{2}{*}{ Census day } & \multicolumn{6}{|c|}{ TOM treatment (\% DW in sediment) } \\
\hline & 0 & 0.25 & 0.5 & 0.75 & 1 & 3 \\
\hline 5 & $0.001 \pm 0.000$ & $0.003 \pm 0.001$ & $0.001 \pm 0.000$ & $0.002 \pm 0.001$ & $0.001 \pm 0.000$ & $0.004 \pm 0.000$ \\
\hline 12 & $0.02 \pm 0.00$ & $0.03 \pm 0.01$ & $0.03 \pm 0.01$ & $0.55 \pm 0.18$ & $1.33 \pm 0.21$ & $1.52 \pm 0.12$ \\
\hline 19 & $0.02 \pm 0.01$ & $0.09 \pm 0.06$ & $0.31 \pm 0.25$ & $2.96 \pm 1.07$ & $3.15 \pm 0.13$ & $4.37 \pm 0.32$ \\
\hline 26 & $0.03 \pm 0.01$ & $0.36 \pm 0.23$ & $0.22 \pm 0.06$ & $5.27 \pm 2.11$ & $4.17 \pm 0.19$ & $9.70 \pm 2.32$ \\
\hline 33 & $0.03 \pm 0.01$ & $2.07 \pm 1.18$ & $2.52 \pm 0.97$ & $6.04 \pm 2.47$ & $8.21 \pm 0.47$ & $11.24 \pm 0.59$ \\
\hline 40 & - & $2.28 \pm 0.13$ & $3.00 \pm 0.88$ & $6.20 \pm 2.42$ & $9.88 \pm 2.46$ & $9.81 \pm 1.94$ \\
\hline 47 & - & $2.16 \pm 1.05$ & $2.73 \pm 0.75$ & $6.59 \pm 1.39$ & $6.90 \pm 2.45$ & $10.82 \pm 1.71$ \\
\hline
\end{tabular}




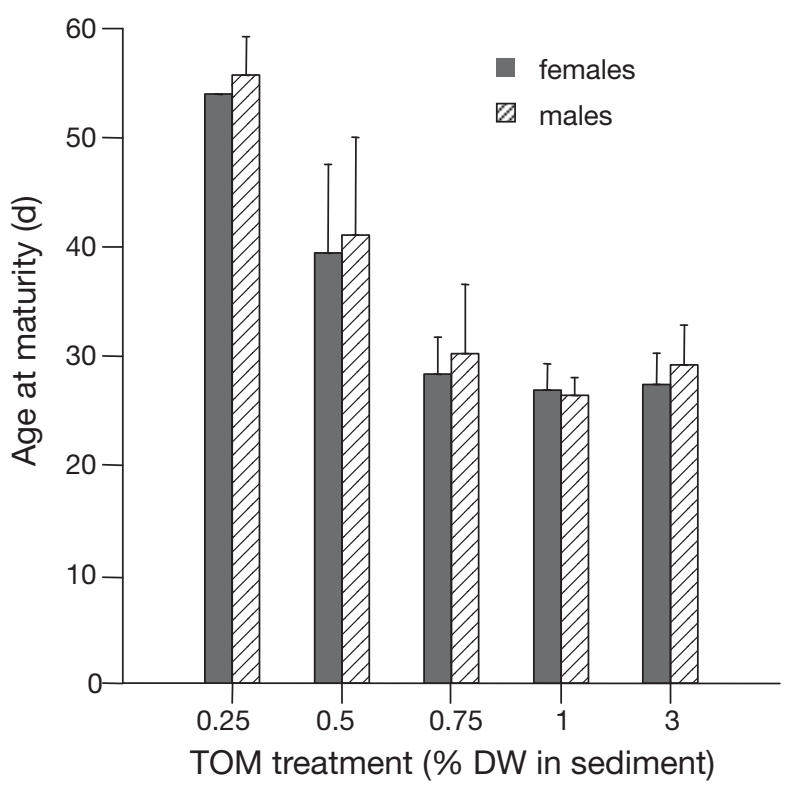

Fig. 2. Capitella sp. I. Average age $(\mathrm{d}$, mean $\pm \mathrm{SD})$ at sexual maturity for females and males in different TOM treatments

successfully. Although worms fed on 0.5\% TOM reproduced over an average of $33 \mathrm{~d}$ and worms in $0.75 \%$ TOM reproduced over an average of $62 \mathrm{~d}$ (the longest period for all treatments), organic matter concentration had only a marginally significant effect on the average duration of the reproductive period (ANOVA, p = 0.098) as a result of high within-treatment variability.

Worms in 1 and $3 \%$ TOM started to reproduce significantly earlier (ANOVA, $\mathrm{p}<0.001$ ) than worms in

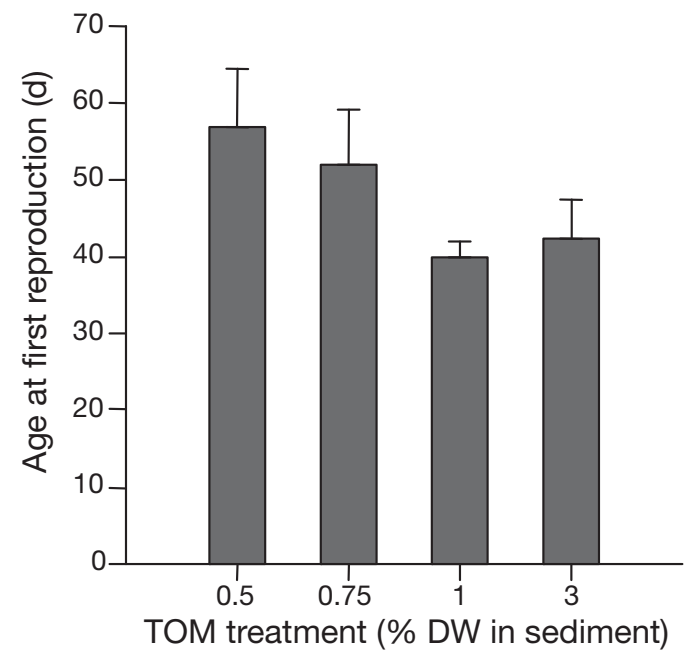

Fig. 3. Capitella sp. I. Average female age $(d$, mean $\pm \mathrm{SD})$ at first reproduction in different TOM treatments. There are no data presented for 0.25 treatments in Figs. 3 to 7 because, although they reached maturity, no worms reproduced in this treatment
0.5 and $0.75 \%$ TOM (Fig. 3). Also mean body sizes of females at their first breeding attempt were strongly affected by treatment (ANOVA, $p=0.004$ ), and worms fed on sediment containing $0.5 \%$ TOM had significantly smaller body volumes (Tukey, p $\leq 0.041$ ) compared to all other treatments (Fig. 4). Though reproductive output (i.e. no of eggs per brood) at the first breeding attempt was only marginally affected by organic matter concentration (ANCOVA, $p=0.096$ ), as well as by differences in female body size (ANCOVA, $\mathrm{p}=0.090)$, there was a significant treatment $x$ body size interaction (ANCOVA, $p=0.025$ ). Female age did not have any effect on the average number of eggs produced at the first breeding attempt (ANCOVA, p = 0.179). However, brood sizes became markedly smaller as a function of female age (days) in the 1 and $3 \%$ TOM treatments, for which the average number of eggs per brood was reduced by up to $75 \%$ between the first and last breeding attempt. Reproductive output seemed to be independent of female age in the 0.5 and $0.75 \%$ TOM treatments.

Time between broods was similar among treatments with approximately 1 breeding attempt $\mathrm{wk}^{-1}$ (ANOVA, $\mathrm{p}=0.271$ ). In contrast, treatment had a strong effect on average number of eggs per reproducing female (ANOVA, p < 0.001), average number of broods (ANOVA, $\mathrm{p}=0.004$ ), and average brood size (ANOVA, $\mathrm{p}<$ 0.001). However, these differences were not monotonically related to TOM. The largest number of eggs over the reproductive period was found in 1\% TOM, which differed significantly from the $\leq 0.75 \%$ TOM treatments (Tukey, $\mathrm{p}<0.014$ ). Individuals in the $3 \%$ TOM treatment produced the second largest number of

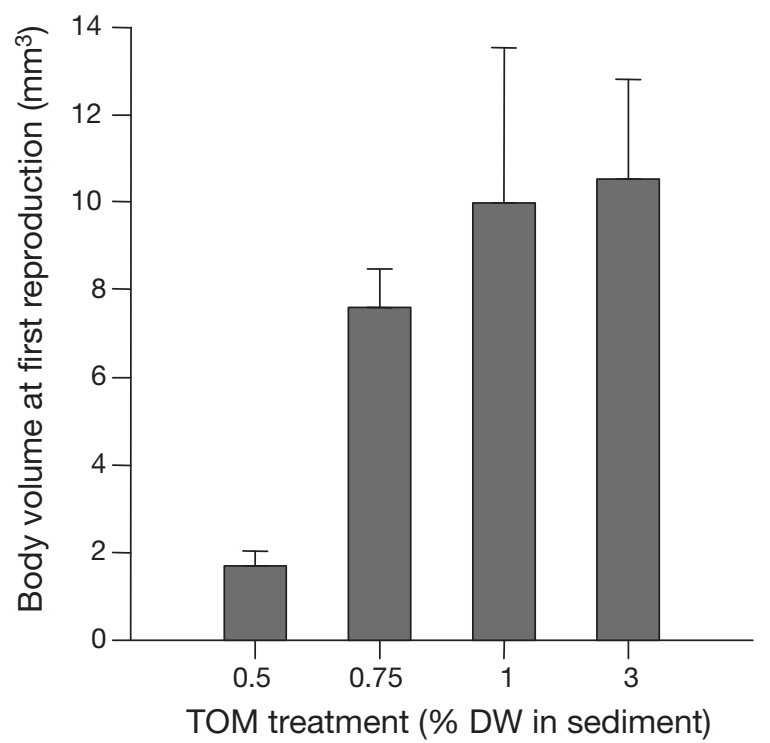

Fig. 4. Capitella sp. I. Average female body size $\left(\mathrm{mm}^{3}\right.$, mean \pm SD) at first breeding attempt in different TOM treatments 
eggs, and significantly more than worms in $0.5 \%$ TOM (Tukey, $\mathrm{p}=0.014$ ). Interestingly, individuals in $0.75 \%$ TOM produced more broods compared to worms in 0.5 and $3 \%$ TOM (Tukey, $p<0.029$ ). The overall effect on average brood size was a considerable reduction at TOM concentrations of 0.5 and $0.75 \%$ compared to TOM concentrations of 1 and $3 \%$ (Tukey, p < 0.001) (Fig. 5).

Overall, worms fed on $0.5 \%$ TOM had the shortest reproductive period and reproduced the fewest times, with the smallest brood sizes, which resulted in a low lifetime fecundity per reproducing female. Although worms in $0.75 \%$ TOM produced the largest number of broods, brood sizes were relatively small, resulting in intermediate lifetime fecundities compared to worms fed on sediments with TOM contents $\geq 1 \%$, for which the highest lifetime fecundities were found.

\section{Population growth rate $(\lambda)$}

As outlined above, individual-level life-history traits in Capitella sp. I changed considerably in response to sediment organic concentration. These changes in lifehistory traits were combined to provide an estimate of population-level impacts, here estimated as $\lambda$. Population growth rates were effectively zero for worms fed on organic matter concentrations of 0 and $0.25 \%$ TOM, since worms in these treatments suffered from high juvenile mortality and did not reproduce.

All other treatments had mean $\lambda$ (given in units of $\lambda$ per week) well above 1 (Fig. 6), suggesting that sedi-

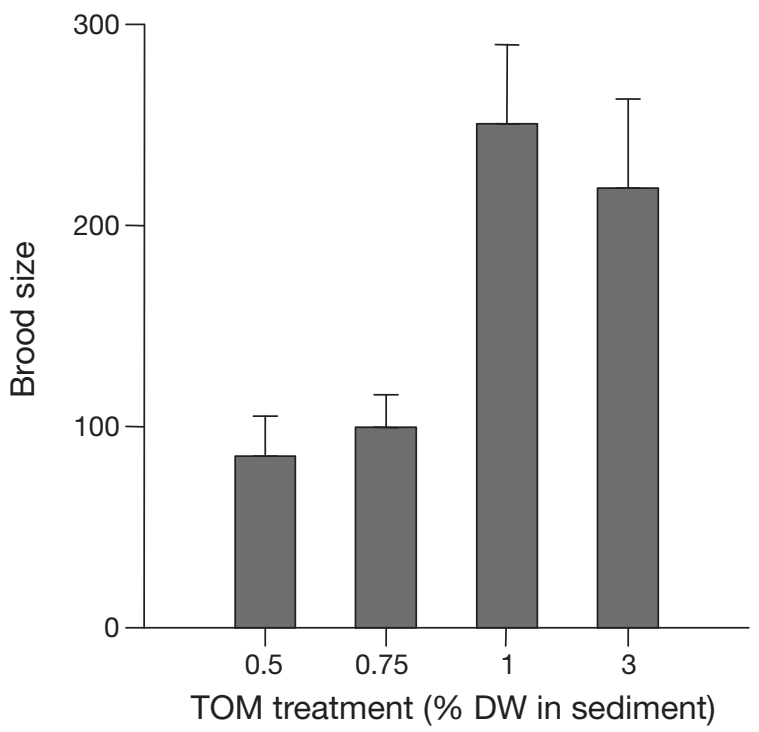

Fig. 5. Capitella sp. I. Average brood size (i.e. number of eggs per brood averaged over reproductive period, mean \pm SD) in different TOM treatments

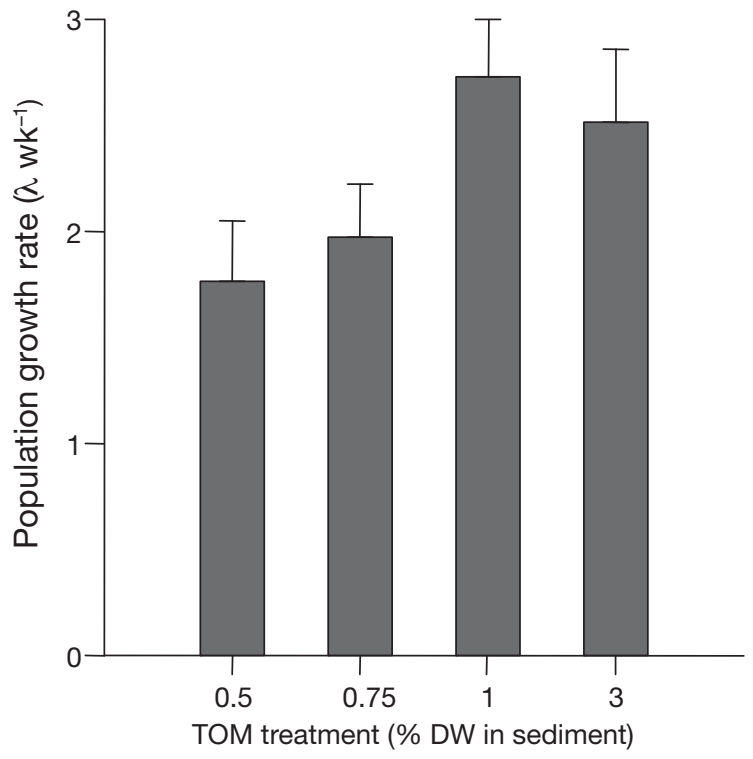

Fig. 6. Capitella sp. I. Population growth rate in different TOM treatments. Error bars represent 95\% confidence intervals

ment organic matter concentrations and conditions similar to those in the present study would be sufficient to support worm populations. Effects on population dynamics were not monotonically related to TOM content. Highest $\lambda$ was found in $1 \%$ TOM, which differed significantly (i.e. defined by non-overlapping $95 \%$ confidence limits) from the 0.5 and $0.75 \%$ TOM treatments, which had the lowest $\lambda$ values. At the highest organic matter concentration, $3 \%$ TOM, the second highest $\lambda$ was found; however, it only differed significantly from $\lambda$ in the lowest organic matter treatment, $0.5 \%$ TOM. No significant differences were observed between the 2 lowest organic matter concentrations or between the 2 highest.

\section{Elasticity analysis}

Elasticity analysis examines the relative sensitivity of $\lambda$ to changes in the individual life-history traits contributing to it. In the present study, $\lambda$ was several times more sensitive to changes in juvenile survival $\left(p_{\mathrm{j}}\right)$ and time to first reproduction $\left(t_{\mathrm{j}}\right)$ compared to all other traits (Fig. 7). There were hardly any differences in the elasticity pattern of juvenile survival among treatments, whereas the relative sensitivity of $\lambda$ to changes in time to first reproduction markedly increased at 1 and $3 \%$ TOM. In contrast, $\lambda$ appeared to be rather insensitive to changes in adult survival $\left(p_{\mathrm{a}}\right)$, time between breeding attempts $\left(t_{\mathrm{a}}\right)$, and fecundity $(n)$ in all treatments. 


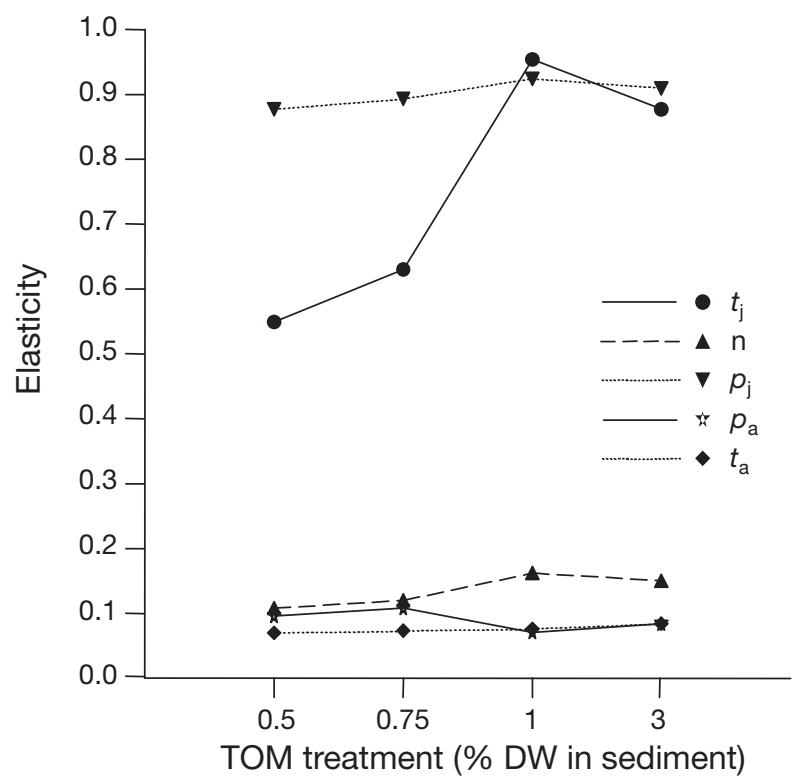

Fig. 7. Capitella sp. I. Elasticity of time to first reproduction $\left(t_{\mathrm{j}}\right)$, fecundity $(n)$, time between production of broods $\left(t_{\mathrm{a}}\right)$, juvenile survival $\left(p_{\mathrm{j}}\right)$, and adult survival $\left(p_{\mathrm{a}}\right)$ in different TOM treatments

\section{Decomposition of treatment effects on $\lambda$}

Decomposition analysis quantifies the relative contributions of each life-history trait to the observed impact on $\lambda$. Since the $1 \%$ TOM treatment resulted in the highest individual-level, as well as populationlevel performance, this treatment was defined as the control for the decomposition analyses, and all effects on population dynamics were compared with reference to this treatment. The contributions of single lifehistory traits to treatment effects on $\lambda$ are shown in Fig. 8.

Adult survival and time between broods contributed very little to the observed changes in $\lambda$, which is explained by the fact that the values of these parameters did not vary much in response to treatment. The insignificant effect in the $3 \%$ TOM treatment on $\lambda$ derives from a balance between a small positive contribution from adult survival and small negative contributions from age at first reproduction, juvenile survival, fecundity, and timing of reproduction events. In contrast, the significantly decreased $\lambda$ values in the 0.5 and $0.75 \%$ TOM treatments were mostly due to delayed age at first reproduction and secondarily to reduced fecundity and juvenile survival.

Summed over treatments, the decomposition analysis showed that total variance in mean $\lambda$ was primarily attributable to treatment effects on time to first reproduction, which explained, on average, $47 \%$ of the variance in $\lambda$. Treatment effects on juvenile survival and fecundity explained, on average, 26 and $24 \%$, respectively, of the observed treatment effect on $\lambda$, whereas adult survival and time between broods together contributed about $3 \%$ to the effect on $\lambda$.

\section{DISCUSSION}

In the present study we quantified the effect of varying the organic matter concentration of a wellcharacterized and relatively nutritional food source on individual performance and population dynamics of Capitella sp. I. We quantified how and to what extent impacts of changing organic content on individual survival, growth, and reproduction play in population dynamics. This information provides insight into the mechanisms underlying the classic 'boom-bust' population dynamics of this species in the field, is helpful for designing experimental studies, and may be used to develop more sophisticated population models to incorporate spatial and/or temporal variability in sediment properties on Capitella population dynamics.
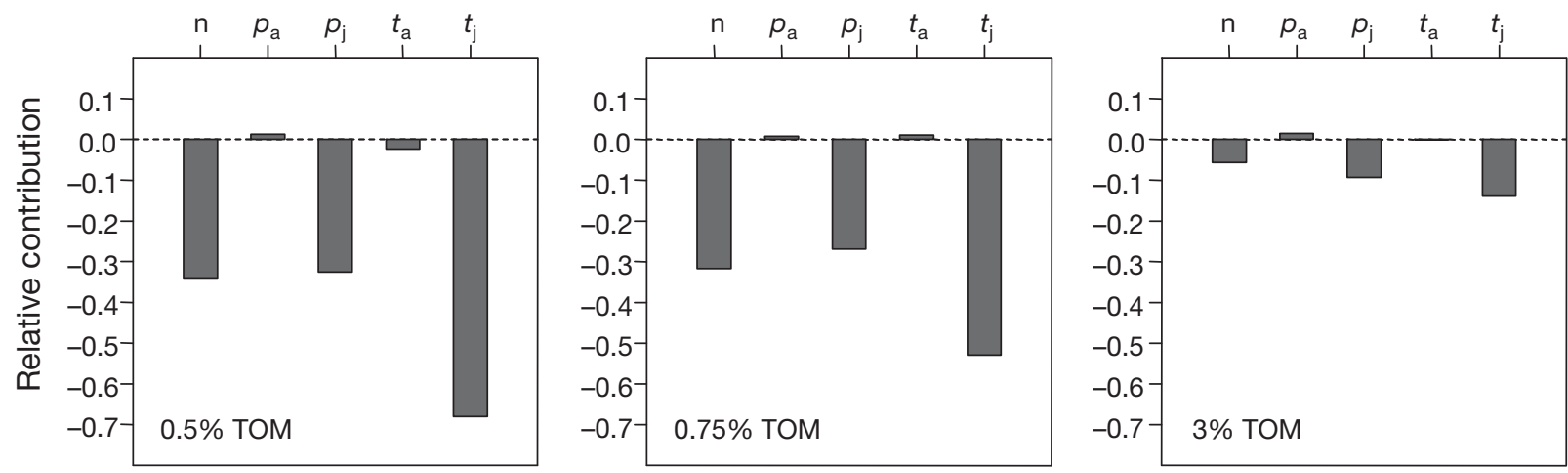

Fig. 8. Capitella sp. I. Decomposition analysis (relative contribution of each life-history trait to observed effect on population growth rate) in different TOM treatments (\% DW in sediment). $t_{\mathrm{j}}$ : time to first reproduction; $n$ : fecundity; $t_{\mathrm{a}}$ : time between production of broods; $p_{\mathrm{j}}$ : juvenile survival; $p_{\mathrm{a}}$ : adult survival 


\section{Individual-level responses}

Our results support previous work indicating the importance of sediment organic content for early larval and juvenile survival and growth (e.g. Marsh et al. 1989, Tsutsumi et al. 1990, Cohen \& Pechenik 1999, Thiyagarajan et al. 2006). In the present study, we did not attempt to measure hatching success as a function of TOM; however, we did observe that, when larvae were $5 \mathrm{~d}$ of age, the minimum number of surviving larvae (i.e. 40) was found in the $0 \%$ TOM treatment, whereas the maximum number of surviving larvae (i.e. 145) was found in the $0.5 \%$ TOM treatment. Obvious differences in growth rates among treatments were apparent on all census days, i.e. already after $1 \mathrm{wk}$ of exposure and during the remaining course of the experiment. This correlation between rapid growth and early maturation of Capitella sp. I in sediments of higher organic content is consistent with previous studies (e.g. Bridges et al. 1994, Levin et al. 1996, Linton \& Taghon 2000). Juvenile survivorship and growth were both considerably impaired in the lower TOM treatments, and the results of the present study suggest that the minimum organic matter concentration for the maintenance (survival and growth) of Capitella sp. I is $0.2 \%$ TOM (i.e. the actual concentration measured in the $0 \%$ TOM treatment), or about $1 \mathrm{mg} \mathrm{C} \mathrm{g}^{-1}$ DW sediment and $0.01 \mathrm{mg} \mathrm{N} \mathrm{g}^{-1} \mathrm{DW}$ sediment. It would appear that a concentration of at least $0.5 \%$ TOM, $2.5 \mathrm{mg} \mathrm{C} \mathrm{g}^{-1} \mathrm{DW}$ sediment and $0.2 \mathrm{mg} \mathrm{N} \mathrm{g}^{-1} \mathrm{DW}$ sediment is necessary for Capitella sp. I to reproduce. It should be stressed, however, that the suggested threshold values assume that the organic matter is digestible and of relatively high quality, which may not be the case in many field situations. For example, Hu et al. (2003) suggested that the minimum food concentration for Capitella sp. I to survive should be $0.15 \mathrm{mg} \mathrm{N}$ $\mathrm{g}^{-1}$ sediment and $1.2 \mathrm{mg} \mathrm{C} \mathrm{g}^{-1}$ sediment on the basis of a combined field and laboratory experiment. The difference between the minimum recommended nitrogen values between these 2 studies is probably related to the fact that much of the nitrogen in the natural mangrove sediments used by $\mathrm{Hu}$ et al. (2003) was associated with refractory humic material.

Despite differences in exact threshold concentrations related to variability in the quality of sediment organic matter among studies, an important result from the present study was that concentration thresholds for larval settlement and early survival were less than those for juvenile growth and development to maturity, which were less than those for successful reproduction (all for the same organic matter quality and under conditions in which the total amount of ingestible sediment was not limiting). This may help to explain why Capitella sp. I may be found at low densi- ties in organic-poor sediments where they only produce small numbers of larvae (Grassle \& Grassle 1974, 1976, Tsutsumi et al. 1990).

The average number of eggs per brood was the lifehistory trait that showed the most marked response to sediment organic content, and average brood size (averaged over the entire reproductive period) was twice as high for worms fed on $1 \%$ TOM compared to worms fed on $0.5 \%$ TOM. Females in 1 and $3 \%$ TOM started to produce their first brood significantly earlier than worms at lower TOM concentrations. Thus, as a result of higher growth rates, worms fed on highquality sediments reached their reproductive size more quickly, altered energy demands from investing energy in somatic growth to investing in reproduction, and accordingly reproduced earlier than worms fed on lower quality sediments. The larger number of offspring produced in the first breeding attempt by females at higher TOM concentrations was (marginally) associated with the larger body size of females, as also shown in other experiments (e.g. Grémare et al. 1988, Bridges et al. 1994, Linton \& Taghon 2000).

Growth rates decreased over time in all treatments; however, the decline was more marked for worms in 1 and $3 \%$ TOM, which initially had the highest growth rates. This result suggests that Capitella sp. I grows toward some maximum body size, at a rate limited by sediment organic content, and thereafter devotes most of its energy to reproduction rather than growth. Moreover, brood sizes declined with female age at higher TOM concentrations (last brood size reduced by $\sim 75 \%$ compared to the first brood size at $1 \%$ TOM), indicating that, if there is enough food, worms invest relatively more energy in reproduction at an early age. This has important consequences for population dynamics given that reproduction early in life contributes much more to $\lambda$ than reproduction later in life (Cole 1954, Lewontin 1965).

Interestingly, all juveniles matured either into females or males, whereas no hermaphrodites were found. This is in contrast to Hansen et al. (1999) and may be due to the fact that, upon morphological maturity, males were selected from the surviving juveniles and reared individually by Hansen et al. (1999). All of these isolated males developed into hermaphrodites. It has been reported that males can develop into hermaphrodites if population density is low, if females are absent or rare, or if males are isolated from conspecifics (Holbrook \& Grassle 1984, Petraitis 1985, 1991). In the present study, juveniles were grown in groups $(n=20)$ until they sexually matured, and population density was relatively high (ca. 10000 worms $\mathrm{m}^{-2}$ ), which may explain why no hermaphrodites were found. At low organic matter concentrations, in which population density was lower due to juvenile mortality, 
male-to-hermaphrodite transitions (i.e. protandry) could potentially have had a positive effect on $\lambda$, since it has been reported that hermaphrodites, although rarely, can undergo self-fertilization (Grassle 1980). However, no changes in gender were observed during the course of the experiment, suggesting either that density in the low TOM treatments was not low enough to cause hermaphroditism or that there are energetic costs involved in changing sex and that these could not be met in the low TOM treatments.

\section{Population-level responses}

The importance of $\lambda$ as an ecologically relevant parameter for assessing stressor impacts on population dynamics is increasingly recognized, e.g. as evidenced by the growing use of demographic models in conservation biology, ecotoxicological studies, and environmental risk assessment (e.g. Barnthouse et al. 2007, Akçakaya et al. 2008). Although individual-level lifehistory traits, such as survival, growth, and reproduction, are all expected to relate to fitness, the relationships between life-history traits and $\lambda$ are neither linear nor consistent (Forbes \& Calow 1999). Changes in single life-history traits (e.g. in response to stressors) do not necessarily correspond to equivalent changes in population growth rate, and changes in $\lambda$ are not necessarily driven by changes in the most stressor-sensitive life-history trait (Kammenga et al. 1996, Levin et al. 1996, Forbes \& Calow 1999). The extent to which $\lambda$ responds to environmental stressors depends on not only the severity of the effects on the individual lifehistory traits, but also on the sensitivity of $\lambda$ to changes in each of the individual life-history traits contributing to it (de Kroon et al. 1986, Caswell 2001).

The range of TOM concentrations used in the present study extended from those resulting in population extinction to those resulting in positive rates of growth, and the threshold between population extinction and population increase was very sharp. Whereas populations in $0.25 \%$ TOM essentially went extinct ( 7 of 11 surviving worms became morphologically mature, but never reproduced), populations in $0.5 \%$ TOM showed a growth rate of approximately $1.8 \mathrm{wk}^{-1}$ (meaning that at this concentration the population nearly doubled in size in a single week). This result suggests that very small variations in sediment organic content can have dramatic consequences for the population dynamics of this species. Given that the highest densities so far reported for field populations of Capitella spp. are from heavily organically polluted sites (Tsutsumi 1987, Mendez et al. 1997), it is interesting that the highest $\lambda$ was found at $1 \%$ TOM and not at $3 \%$ TOM. It is possible that lowered oxygen levels in the highest TOM treatment had a negative effect on worm performance; however, efforts were made to keep oxygen concentrations high, and worms burrowed actively in the sediment throughout the experiment.

The effect of a change in a given life-history trait for population dynamics depends both on the degree of change in the trait (e.g. its sensitivity to environmental variables) and its elasticity (Caswell 2001). Integrating life-history responses to environmental stressors using demographic models allows both interpretation of the likely demographic consequences of changes in lifehistory traits and provides a mechanistic explanation for observed changes in population dynamics. For example, despite the substantial stimulatory effect on brood size observed for worms fed on more organicrich sediment $(66 \%$ difference between the 0.5 and $1 \%$ TOM treatments), the effect of increased brood size was attenuated at the population level due to a relatively low elasticity of this trait. In contrast, the elasticities of juvenile survival and timing of first reproduction were substantially higher than the other lifehistory traits, suggesting that a given impact on juvenile survival and time to first reproduction could be expected to have much greater consequences for population dynamics of Capitella sp. I than would a similar proportional impact on adult survival, fecundity, or time between breeding attempts.

However, since effects are seldom equally distributed among traits, and hence, elasticity analysis only deals with hypothetical impacts of changing lifehistory traits on $\lambda$, decomposition analysis is necessary to determine which life-history traits are responsible for observed differences in $\lambda$ under a given set of experimental conditions (Caswell 1989, Levin et al. 1996). This analysis indicated that adult survival and time between broods did not contribute to the observed changes in $\lambda$. This is explained by both the low elasticities of these traits as well as the fact that they were not (significantly) affected by treatment. Instead a treatment effect on time to first reproduction was the major cause of the observed change in $\lambda$. Although time to first reproduction was not the most treatment-sensitive life-history trait, its high elasticity resulted in effects on it making the greatest contribution to the population dynamics. The importance of this life-history trait for $\lambda$ has been emphasized both theoretically (e.g. Cole 1954, Lewontin 1965) and analytically (e.g. Kammenga et al. 1996, Levin et al. 1996, Hansen et al. 1999), stressing that the explosive responses to organic enrichment of Capitella sp. I are driven primarily by reduced age at first reproduction. Apart from timing of reproduction, the observed differences in $\lambda$ were attributable to changes in juvenile survival and fecundity, which each explained approximately $25 \%$ of the observed effect on $\lambda$. These 3 traits were negatively 
affected by 43,27 and $66 \%$, respectively, in the $0.5 \%$ TOM compared to the $1 \%$ TOM treatment, and these individual-level traits contributed to a total impact on $\lambda$, which was reduced by $35 \%$. Thus, it is clear that stressor impact (\% change) on any single individuallevel trait may be less than or greater than the effect on $\lambda$. Also, even highly significant effects on individual life-history traits may be buffered at the population level, particularly when different traits are affected in opposite directions.

In conclusion, the observed negative effects of reduced TOM at the individual level occurred at the same concentration as for $\lambda$, supporting the idea that $\lambda$ is equally or less responsive to stressor impact than are the individual life-history traits contributing to it. However, as indicated in the present and earlier studies (e.g. Forbes \& Calow 1999), the most sensitive individuallevel life-history variables can be difficult to identify a priori. There is therefore a need for development of general principles that can improve the predictability of demographic models for various applications, and this includes determining the extent to which demographically important life-history traits are generally more or less sensitive to environmental stressors than are less important traits (Kammenga et al. 1996, Pfister 1998, Forbes \& Calow 1999, 2002). If consistent relationships between the elasticities of life-history traits and their relative sensitivity to environmental stressors can be identified, understanding and predicting impacts of stress on populations could be improved.

Acknowledgements. We thank H. Selck and A. Palmqvist for valuable discussions on the design and interpretation of the experiments.

\section{LITERATURE CITED}

Akçakaya HR, Stark JD, Bridges TS (eds) 2008. Demographic toxicity: case studies in ecological risk assessment. Oxford University Press, Oxford

Barnthouse LW, Munns WR Jr, Sorensen MT (2007) Population-level ecological risk assessment. Taylor \& Francis, Boca Raton, FL

Bridges TS, Levin LA, Cabrera D, Plaia G (1994) Effects of sediment amended with sewage, algae, or hydrocarbons on growth and reproduction in two opportunistic polychaetes. J Exp Mar Biol Ecol 177:99-119

Calow P, Sibly RM (1990) A physiological basis of population processes: ecotoxicological implications. Funct Ecol 4: 283-288

Calow P, Sibly RM, Forbes VE (1997) Risk assessment on the basis of simplified life-history scenarios. Environ Toxicol Chem 16:1983-1989

> Caswell H (1989) Analysis of life table response experiments. I. Decomposition of effects on population growth rate. Ecol Modell 46:221-237

Caswell H 2001. Matrix population models, 2nd edn. Sinauer Associates, Sunderland, MA

Charles F, Amouroux JM, Grémare A, Baudart J (1995) A bio- assay approach to temporal variation in the nutritional value of sediment trap material. J Exp Mar Biol Ecol 191:65-81

Cohen RA, Pechenik JA (1999) Relationship between sediment organic content, metamorphosis, and postlarval performance in the deposit-feeding polychaete Capitella sp. I. J Exp Mar Biol Ecol 240:1-18

Cole LC (1954) The population consequences of life history phenomena. Q Rev Biol 29:103-137

de Kroon HD, Plaisier A, van Groenendael J, Caswell H (1986) Elasticity, the relative contribution of demographic parameters to population growth rate. Ecology 67: 1427-1431

Decho AW, Lopez GR (1993) Exopolymer microenvironments of microbial flora: multiple and interactive effects on trophic relationships. Limnol Oceanogr 38:1633-1645

Forbes VE, Calow P (1999) Is the per capita rate of increase a good measure of population-level effects in ecotoxicology? Environ Toxicol Chem 18:1544-1556

Forbes VE, Calow P (2002) Population growth rate as a basis for ecological risk assessment of toxic chemicals. Philos Trans R Soc Lond B 357:1299-1306

Forbes VE, Calow P, Sibly RM (2001) Are current species extrapolation models a good basis for ecological risk assessment? Environ Toxicol Chem 20:442-447

Grassle J (1980) Polychaete sibling species. In: Brinkhurst RO, Cook DG (eds) Aquatic oligochaete biology. Plenum Press, New York, p 25-32

Grassle JF, Grassle JP (1974) Opportunistic life histories and genetic systems in marine benthic polychaetes. J Mar Res 32:253-284

Grassle JF, Grassle JP (1976) Sibling species in the marine pollution indicator Capitella (Polychaeta). Science 192: 567-569

Grémare A, Marsh AG, Tenore KR (1988) Short-term reproductive responses of Capitella sp. I (Annelida: Polychaeta) fed on different diets. J Exp Mar Biol Ecol 123:147-162

> Grémare A, Amouroux JM, Charles F, Dinet A and others (1997) Temporal changes in the biochemical composition and nutritional value of the particulate organic matter available to surface deposit-feeders: a two year study. Mar Ecol Prog Ser 150:195-206

> Hansen K, Kristensen E (1997) Impact of macrofaunal recolonisation on benthic metabolism and nutrient fluxes in a shallow marine sediment previously overgrown with macroalgal mats. Estuar Coast Shelf Sci 45:613-628

$>$ Hansen FT, Forbes VE, Forbes TL (1999) Effects of 4-nnonylphenol on life-history traits and population dynamics of a polychaete. Ecol Appl 9:482-495

> Holbrook MJL, Grassle JP (1984) The effect of low density on the development of simultaneous hermaphroditism in male Capitella species I (Polychaeta). Biol Bull 166:103-109

Hu SI, Horng CY, Cheng IJ (2003) The use of growth and ingestion rates of Capitella sp. I as the bioassay approaches to determine the sediment quality of coastal wetlands of Taiwan. J Exp Mar Biol Ecol 297:179-202

> Jacobsen R, Forbes VE, Skovgaard O (1996) Genetic population structure of the prosobranch snail Potamopyrgus antipodarum (Gray) in Denmark using PCR-RAPD fingerprints. Proc R Soc Lond B 263:1065-1070

Kammenga JE, Busschers M, van Straalen NM, Jepson PC, Bakker J (1996) Stress induced fitness reduction is not determined by the most sensitive life-cycle trait. Funct Ecol 10:106-111

Kaufmann KW (1981) Fitting and using growth curves. Oecologia 49:293-299

Levin L, Caswell H, Bridges T, Dibacco C, Cabrera D, Plaia G (1996) Demographic responses of estuarine polychaetes to sewage, algal, and hydrocarbon additions: life-table 
response experiments. Ecol Appl 6:1295-1313

Lewontin RC (1965) Selection for colonizing ability. In: Baker HG, Stebbins GL (eds) The genetics of colonizing species. Academic Press, New York

Linke-Gamenick I, Forbes VE, Méndez N (2000) Effects of chronic fluoranthene exposure on sibling species of Capitella with different development modes. Mar Ecol Prog Ser 203:191-203

Linton DL, Taghon GL (2000) Feeding, growth and fecundity of Capitella sp. I in relation to sediment organic concentration. Mar Ecol Prog Ser 205:229-240

Lopez GR, Levinton JS (1987) Ecology of deposit-feeding animals in marine sediments. Q Rev Biol 62:235-260

Marsh AG, Grémare A, Tenore KR (1989) Effect of food type and ration on growth of juvenile Capitella sp. I (Annelida: Polychaeta): macro- and micronutrients. Mar Biol 102: 519-527

Mendez N, Romero J, Flos J (1997) Population dynamics and production of the polychaete Capitella capitata in the littoral zone of Barcelona (Spain, NW Mediterranean). J Exp Mar Biol Ecol 218:263-284

Petraitis PS (1985) Digametic sex determination in the marine polychaete, Capitella capitata (species type I). Heredity 55:151-156

$>$ Petraitis PS (1991) The effects of sex ratio and density on the expression of gender in the polychaete Capitella capitata. Evol Ecol 5:393-404

Pfister CA (1998) Patterns of variance in stage-structured

Editorial responsibility: Pei-Yuan Qian,

Kowloon, Hong Kong, SAR populations: evolutionary predictions and ecological implications. Proc Natl Acad Sci USA 95:213-218

Rossi F, Como S, Corti S, Lardicci C (2001) Seasonal variation of a deposit-feeder assemblage and sedimentary organic matter in a brackish basin mudflat (western Mediterranean, Italy). Estuar Coast Shelf Sci 53:181-191

Sanders HL, Grassle JF, Hampson GR, Morse LS, GarnerPrice S, Jones CC (1980) Anatomy of an oil spill: long-term effects from the grounding of the barge Florida off West Falmouth, Massachusetts. J Mar Res 38:265-380

Self RFL, Jumars PA (1978) New resource axes for deposit feeders? J Mar Res 36:627-641

> Sibly RM, Hansen FT, Forbes VE (2000) Confidence intervals for population growth rate of organisms with two-stage life histories. Oikos 88:335-340

Tenore KR (1988) Nitrogen in benthic food chains. In: Blackburn TH, Sørensen J (eds) Nitrogen cycling in coastal marine environments. John Wiley, London, p 191-206

Thiyagarajan V, Soo L, Shin PKS, Qian PY (2006) Spatio-temporal variation in sediment biochemistry alters larval habitat selection and juvenile performance in the polychaete Capitella sp. I. Mar Ecol Prog Ser 327:207-222

Tsutsumi H (1987) Population dynamics of Capitella capitata (Polychaeta, Capitellidae) in an organically polluted cove. Mar Ecol Prog Ser 36:139-149

Tsutsumi H, Fukunaga S, Fujita N, Sumida M (1990) Relationship between growth of Capitella sp. and organic enrichment of the sediment. Mar Ecol Prog Ser 63:157-162

Submitted: October 17, 2007; Accepted: May 21, 2008

Proofs received from author(s): September 29, 2008 